Artículo de investigación

Apuntes del CENES

ISSN 0120-3053

Volumen $34-\mathrm{N}^{\circ} .59$

Enero - Junio de 2015

Págs. 93-124

\title{
Perfil espacial de la economía boyacense
}

\author{
A spatial profile of the economy of Boyacá \\ Perfil do espaço na economia de Boyacá
}

Helmuth Yesid Arias Gómez*

Gabriela Antošová**

Fecha de recepción: 1 de septiembre de 2014

Concepto de evaluación: 21 de noviembre de 2014

Fecha de aprobación: 28 de noviembre de 2014

* Estudiante Doctorado en análisis económico aplicado e historia económica, Universidad de Sevilla. Magíster en Ciencias Económicas, Universidad Nacional de Colombia. Bogotá, Colombia. Correo electrónico: hyarias@gmail.com

** Doctora de la Universidad Agrícola Checa, Departamento de Humanidades. Praga, República Checa. Correo electrónico: antosovag@pef.czu.cz 


\title{
Resumen
}

Se intenta describir la economía boyacense en términos espaciales con la identificación de conjuntos de municipios, que por su contigüidad, pueden compartir algunas características productivas y geográficas comunes. Con las variables económicas georreferenciadas disponibles se aplican algunas herramientas de análisis espacial para determinar la tendencia de localización de las actividades agrícolas, industriales y de servicios. El desarrollo del tema corrobora las intuiciones teóricas que destacan la conformación de núcleos urbanos centrales que concentran actividades económicas y de zonas periféricas con baja productividad y sumidas en un estancamiento económico a causa de su aislamiento y la precariedad de la conectividad.

Palabras clave: análisis espacial, economía regional, estructura productiva, localización de la producción.

Clasificación JEL: C18, R12, R15

\begin{abstract}
This article aims to make a description of economy in Colombian region of Boyacá, in terms of its spatial implications, identifying a set of municipalities that share some mutual features of productive and geographical sort. Using disposable geo referential information some tools of spatial analysis were applied, in order to find out the spatial features in the agricultural production, and industrial and services unities. In doing so, some theoretical clues are confirmed in the sense that some urban and central places concentrate economic activities, while some local peripheries show low productivity and remain stagnant, as consequence of geographical isolation and poor connectivity.
\end{abstract}

Keywords: spatial analysis, regional economics, structure of production, location of production.

\section{Resumo}

Este trabalho tem como objetivo descrever a economia Boyacense em termos espaciais, com a identificação de grupos de municípios que, pela sua contiguidade podem compartilhar algumas características produtivas e geográficas comuns. Com as variáveis econômicas disponíveis algumas ferramentas de análise espacial geo-referenciadas são aplicados para determinar a natureza espacial das atividades agrícolas, industriais e de serviços. O desenvolvimento do tema corrobora conhecimentos teóricos que destacam a criação de centros urbanos centrais que concentram áreas económicas e periferias, com atividades de baixa produtividade e relegadas na estagnação econômica com resultado do seu isolamento e pobre conectividade.

Palavras-chave: análise espacial, economia regional, estrutura produtiva. localização da produção. 


\section{INTRODUCCIÓN}

El departamento de Boyacá es contado dentro de los cuatro principales productores agrícolas del país (PNUD, 2011), gracias a una inveterada tradición productiva de economía campesina y a una variedad de climas y condiciones naturales. En otras circunstancias, cuando la naturaleza no permite explotar la agricultura de forma productiva, los municipios han buscado sobrevivir en actividades de servicios, como el turismo, el comercio, en la artesanía o en la alfarería.

En efecto, la economía boyacense se ha caracterizado por ser predominantemente agrícola y minera, aunque en los años recientes los servicios han ganado una mayor participación en la producción del departamento (Rodríguez, 2007). Esta modificación sectorial de la estructura productiva se refleja en la distribución espacial de la actividad económica que se visualiza en los despliegues cartográficos y de análisis espacial.

Este impacto sobre las dimensiones espaciales resalta la importancia del análisis de la localización de las variables económicas, y la posible persistencia de un determinado fenómeno espacialmente localizado en sitios particulares y en sus vecindades. Según esto, existen condiciones comunes compartidas por un conjunto de municipios, las cuales ayudan a comprender la vocación productiva de alguna comarca en particular y permiten determinar ciertas condiciones geográficas o naturales que subyacen a estos fenómenos espaciales.

Como es ampliamente conocido, desde la época de Alfred Marshall ya se discutía que la influencia más primaria para la localización de la actividad productiva 
provenía del condicionamiento natural y el acceso a los recursos naturales. Las observaciones del autor británico surgieron de la curiosidad que le despertaba la ubicación de la industria en la Inglaterra de finales del siglo XIX (Marshall, 2005). En este contexto, el departamento de Boyacá posee suelos fértiles que albergan una variedad de actividades productivas, pero también en algunas comarcas la erosión del suelo y el deterioro de la capa vegetal han dejado huella en algunas zonas desérticas (ver mapa 2). Más adelante se observará también que en las zonas más fértiles y con suelos aptos, se erigen algunos municipios que se destacan por su productividad, especialmente en algunos productos en particular.

En atención a lo anterior, este artículo analiza la distribución espacial de las actividades económicas de Boyacá, para lo cual se aplican algunas herramientas básicas del análisis espacial. La información georreferenciada se descargó de la aplicación SIG-OT que está disponible en la página web del Instituto Geográfico Agustín Codazzi (IGAC) ${ }^{1}$, personalizando los datos para el departamento de Boyacá. La información tiene el gran mérito de estar disponible por municipios, aunque por el mismo grado de detalle, no existen estadísticas en el plano de la producción manufacturera o de servicios. No obstante, se incorporaron variables sucedáneas que de manera indirecta $\mathrm{y}$ con alta fidelidad ofrecían indicios de lo que originalmente se pretendía estudiar.
En términos de variables de análisis, la información más completa y directa consultada en el ente geográfico correspondió a la producción agrícola por municipios. Para el caso de la industria manufacturera, no existen estadísticas abiertas a nivel local de la producción, valor agregado o empleo, de modo que para abordar este sector, se utilizó la información municipal del número de unidades productivas, la cual se encontró debidamente georreferenciada. Finalmente, para el sector de servicios la investigación incluyó los datos del número de unidades de servicios para cada municipio. Dada la ventaja de contar con estadísticas municipales en dichos términos, fue posible aplicar una serie de herramientas geoestadísticas para determinar las características y los patrones espaciales de las variables en cuestión y extraer conclusiones muy específicas y locales.

En ese sentido, el artículo logra explorar algunos aspectos espaciales de la producción boyacense y trata de identificar los municipios que tienen determinado papel en la localización de la actividad económica en el departamento. Precisamente, en el anexo 1 que acompaña este documento, se presenta la codificación de los municipios y la división política del departamento, para orientar la ubicación de las jurisdicciones municipales mencionadas repetidamente en el presente análisis.

Puede consultarse: http://sigotn.igac.gov.co/sigotn/ 
La estructura del artículo comprende cinco partes. Después de esta introducción, se presenta una sección que plantea algunas ideas sobre el problema de la localización de la actividad económica siguiendo una clasificación útil aplicada por el premio nobel Krugman (1995), aunque se hace un énfasis en los esquemas conceptuales de Von Thünen, cuya utilidad salta a la vista cuando se observa la disposición espacial de las variables económicas consultadas. En efecto, el despliegue cartográfico exhibe núcleos de producción y de actividad económica en las principales ciudades boyacenses, rodeadas de un conjunto de municipios cercanos, gravitando en torno a ellas de acuerdo con su vocación productiva particular. En la tercera sección se exponen algunos aspectos metodológicos como caja de herramientas para interpretar los resultados subsiguientes. La cuarta parte presenta un análisis espacial básico de las variables georrefereciadas disponibles para la agricultura, la industria manufacturera y los servicios. Finalmente se proponen algunas conclusiones.

\section{MARCO TEÓRICO}

La forma espacial que asume la actividad productiva ha concitado la atención tanto de geógrafos como de economistas. Desde los aportes de la escuela alemana de la localización hasta los recientes desarrollos de la nueva geografía económica mucho se ha escrito e investigado sobre el fenómeno de la aglomeración y la localización en el espacio. Para hacer un recuento de las contribuciones de al- gunos magníficos exponentes acerca del tema, se seguirá la descripción propuesta por Paul Krugman (1995), centrada en enfatizar las dificultades que surgen a la hora de incorporar la línea de estudios de la localización en el corpus teórico básico de la ciencia económica.

La clasificación que propone Krugman (1995) de las tradiciones de pensamiento para explicar la localización, tiene como punto de partida el reconocimiento de la importancia de ubicarse en un contexto de rendimientos crecientes para comprender a cabalidad la distribución desigual de la actividad económica en el espacio. Por el contrario, si se trabaja en un contexto de rendimientos constantes y en presencia de costos de transporte, el mundo mostraría un panorama dominado por un conjunto de cobertizos autosuficientes, en los cuales cada productor se encargaría de producir para su propia satisfacción de manera autárquica, en lo que se ha denominado el capitalismo de la casita con jardin (Krugman 1992, 1995; Fujita et al., 2000). Esta metáfora resalta el papel fundamental de las economías de escala como fuerza de localización, según la cual las firmas se instalan en pocos lugares en donde se detecte la existencia de un mercado suficientemente grande, como para producir amplios volúmenes, explotando unas condiciones de producción dominadas por los rendimientos crecientes.

En ese sentido, la existencia comprobada de concentraciones espaciales de la actividad económica y de una distribución desigual de la producción, es una señal 
inequívoca de la falta de vigencia del capitalismo de la casita con jardín. El objetivo de Krugman (1995) al identificar las cinco tradiciones en la economía espacial, demuestra el intento de este campo de la ciencia por incrustarse en el núcleo central de la ciencia económica convencional.

La primera tradición propuesta corresponde a la geometría germánica ${ }^{2}$, desarrollada entre escritores de lengua alemana y que fue conocida en el contexto anglosajón solo hasta mediados del siglo XX. En esta tradición se puede incluir el modelo en el que las empresas buscan atender varios mercados contando con uno o más proveedores, de modo que tengan más de tres sitios para escoger una localización. Igualmente, tienen cabida las teorías del emplazamiento central que terminan proponiendo soluciones de tipo geométrico con una población agrícola distribuida en forma homogénea, cuyos resultados podrían conducir a una distribución hexagonal de la población agrícola o a un esquema jerarquizado de ciudades.

La cuestión con este tipo de modelos es que son descripciones geométricas de la localización, antes que explicaciones de tipo económico según el análisis convencional. También exhiben una carencia fundamental de un marco microfundamentado, en el cual aparezca una explicación de las decisiones individuales y una definición de la estructura de mercado en cuyo contexto se desarrolle el modelo. En resumen, la principal carencia de estos enfoques consiste en que no es posible explicar la existencia de un emplazamiento central, desconociendo el poder de mercado de las empresas imperfectamente competitivas (Krugman, 1995).

La segunda tradición reseñada por Krugman (1995) es denominada como física social y es identificada con desarrollos ocurridos en Estados Unidos a mediados del siglo $\mathrm{XX}$, los cuales apuntaban a elaborar un conjunto de algoritmos que representaban la relación entre población y rango de las ciudades y el aprovechamiento del potencial de mercado. Estas herramientas resultaron tener una alta precisión práctica y una suficiente capacidad para explicar ciertas regularidades empíricas en materia de localización.

La definición de la regla del tamañorango $^{3}$ relacionaba funcionalmente la distribución del tamaño de las ciudades con el rango de ordenación siguiendo un criterio demográfico. La mencionada regla fue definida como:

$$
\mathrm{N}_{\mathrm{i}}=\frac{\mathrm{k}}{\mathrm{R}_{\mathrm{j}}^{\mathrm{b}}}
$$

siendo $N$ la población de la ciudad $N, R$ su rango de ordenación según el criterio demográfico y $b$ fungiendo como un exponente cercano a 1 .

\footnotetext{
En esta categoría clasifica a teóricos como Weber, Lösch y Christaller. Conocida también como la Ley de Zip.f
} 
Siguiendo con los algoritmos asociados a la fisica social, aparece una expresión de tipo gravitacional en donde intervienen las poblaciones, sus distancias y el volumen de transacciones efectuadas. Una forma de presentarla es:

$$
\mathrm{T}_{\mathrm{ij}}=\mathrm{k} \frac{\mathrm{N}_{\mathrm{i}} \mathrm{N}_{\mathrm{j}}}{\mathrm{D}_{\mathrm{ij}}^{\mathrm{b}}}
$$

en donde $T$ representa las transacciones efectuadas entre ciudades, $D$ es la distancia y $b$ es igualmente un exponente.

Un tercer algoritmo se definió en términos del potencial de mercado, para identificar entidades que demuestren tener un fuerte mercado como una información fundamental para las firmas a la hora de localizarse. Se construyó entonces un índice que incorporó la capacidad adquisitiva de los mercados y las distancias, de la siguiente forma:

$$
p_{i}=\sum_{j} k \frac{Y_{j}}{D^{b}{ }_{i j}}
$$

Con parámetros similares a los anteriores pero incluyendo a $Y$ representando el poder adquisitivo de un determinado mercado. Estas herramientas centradas en el poder de mercado tuvieron un ajuste adecuado a las investigaciones empíricas, y coincidieron en localizar con precisión los puntos en los que se retroalimentaban la aglomeración industrial y los focos de mercado.

La tercera tradición de la economía espacial corresponde a la causalidad acumula- tiva $a^{4}$ que hizo énfasis precisamente en la dependencia circular que se genera entre el potencial de mercado y la ubicación de las firmas. Con estos argumentos se intentó explicar la dinámica autorreforzada presente en el crecimiento de las ciudades como respuesta al desarrollo de la industria, originado a su vez en el crecimiento urbano. Este proceso circular fue plasmado en algunos trabajos empíricos que fueron consistentes con esta hipótesis.

Esta lógica aplicada a la teoría del desarrollo, podía hacer predicciones de lo que pasaría a una escala territorial de alcance regional. En dichos términos, si un mercado fuera lo suficientemente grande como para propiciar economías de escala, podría originarse un proceso de sustitución de importaciones que favoreciera la producción local. A continuación, y en presencia de libre movilidad de factores, la inmigración aumentaría el número de trabajadores y se daría origen a un nuevo ciclo de ampliación de la producción.

Seguidamente, Krugman apela a la influencia tecnológica y a los spillovers que están en la base de la cuarta tradición denominada como externalidades locales. El economista cuya contribución es más reconocida en este sentido es Alfred Marshall (2005), con su énfasis en la transmisión de conocimientos entre firmas por efectos de la cercanía espacial. Aunque en principio sus aportaciones se limitaron a la definición de unas externalidades de tipo puramente tecnológico,

Importantes exponentes son Harris, Lowry, Pred y Myrdal. 
estas fueron incluidas como una de las fuerzas centrípetas de la aglomeración industrial.

Finalmente, en la quinta tradición del análisis de la economía espacial, Krugman alude a los estudios basados en la Renta del suelo y el uso del suelo. Para desarrollar esta tradición se centra en el modelo teórico de los anillos concéntricos en torno a una ciudad aislada ${ }^{5}$.

En el presente análisis se complementará dicho recuento con un análisis gráfico presentado en el trabajo de Cabral (2011), en donde aparece una ilustración de los anillos de Von Thünen en un estudio de la localización de la industria maderera y forestal. Así mismo se consultará un desarrollo más formal del modelo de anillos concéntricos expuesto en la contribución magnífica de Samuelson (1983) que, al abordar el modelo, desarrolla una sofisticación matemática y analítica notable.

El punto de partida del modelo es la funcionalidad de la organización agrícola en torno a una ciudad central, atendiendo a varios condicionamientos económicos y geográficos, como la distancia con respecto al centro urbano, la intensidad factorial (tierra y trabajo) de los cultivos y los costos de transporte. En esas circunstancias, la disposición espacial del modelo muestra un conjunto de anillos circundantes que acogen la producción agrícola, de acuerdo con los usos del suelo en cada segmento espacial.
Cada agricultor tiene características similares a sus pares, pero el elemento diferenciador es la posición geográfica y la distancia con respecto al lugar central, circunstancia que introduce el costo de transporte como criterio central del modelo. Otra implicación es que el incremento de la distancia ejerce un efecto de reducción paulatina de la renta agrícola, coincidiendo con la necesidad de elevar los salarios por el alza del precio del bien urbano. Adicionalmente, la índole diferencial introducida por la distancia, afecta los sistemas de producción agrícola y el tipo de cultivo en cada anillo, reservándose la agricultura intensiva en los anillos centrales y distribuyendo las actividades extensivas en las zonas más alejadas.

El modelo asume criterios importantes, en palabras de Cabral (2011):

- Se trata de una planicie de terreno uniforme en cuanto a la calidad de los suelos con un anillo externo de selva virgen.

- No hay movimientos de exportación e importación más allá de la selva.

- Los agricultores son homogéneos en su nivel cultural.

- El agricultor produce para el mercado procurando maximizar su ingreso.

- El único mercado posible para poner los productos es el mercado urbano.

- Los productos se transportan a la ciudad por intermedio de vehículos de tracción animal.

5 Particularmente la discusión se centra en el aporte de Von Thünen. 


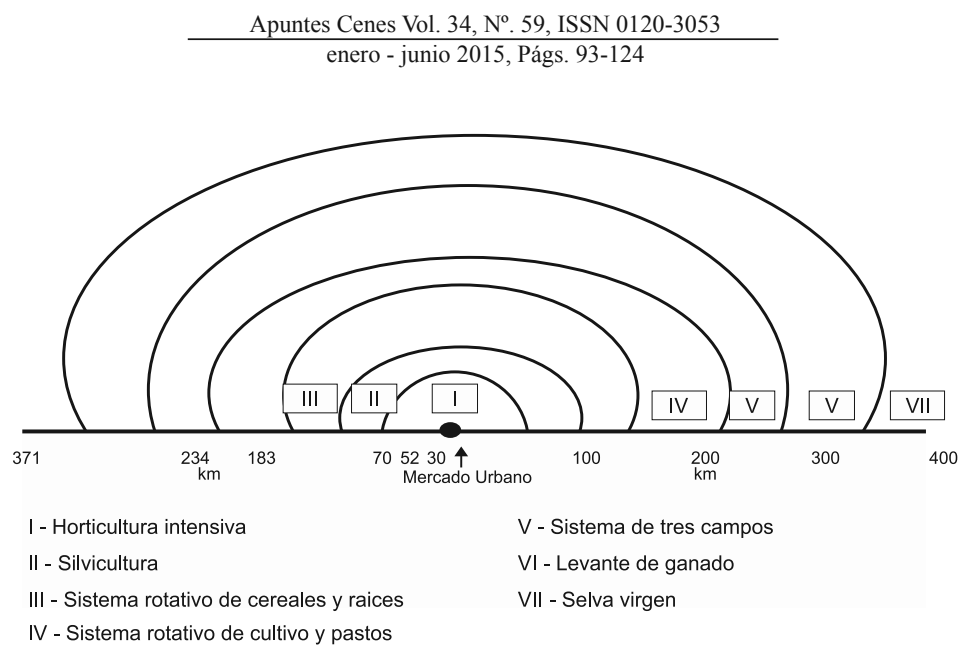

Figura 1. Los Anillos de Von Thünen

Fuente: tomado de Cabral (2011).

En la Figura 1, Cabral desarrolla gráficamente la configuración de los anillos productivos que se derivan del modelo de Von Thünen y su "teoría de los cultivos". En esta distribución espacial es razonable que los productos más costosos de transportar se cultiven en los anillos más centrales, aplicando un criterio de eficiencia económica en esta decisión.

De acuerdo con lo anterior, la organización de la producción agrícola ubicaría en el anillo más central el cultivo de verduras, legumbres y frutas; en un segundo anillo se dispondría la producción de maderas y leña; en el tercero se ubicarían cultivos rotativos de cereales y tubérculos; en el siguiente anillo se organizaría una rotación de cereales y pastos; en el quinto anillo se adecuaría un sistema de tres campos, compuestos por cultivos de invierno, cultivos de primavera y barbecho. Finalmente, al sexto anillo sería relegada la producción pecuaria extensiva (Cabral, 2011).
En el modelo de Von Thünen al estilo Samuelson (1983) se asume la especialización de la ciudad en la producción de vestuario, y de otro lado intervienen dos cultivos agrícolas dispuestos en sus respectivos anillos: por un lado, los vegetales que son más delicados de transportar $\mathrm{y}$, por consiguiente, que acarrean mayores costos y, por otro lado, los granos con bajos costes de transporte. En estas circunstancias, los vegetales serán cultivados en los limitados territorios que son contiguos a la ciudad, mientras que los granos se sembrarían en las planicies más alejadas, por su mayor facilidad de transporte. Por razones de eficiencia económica, la producción será ahorradora del factor tierra cuanto más central sea el anillo. Esto se explica porque la producción tenderá progresivamente a aprovechar intensivamente la tierra, conforme la distancia se incrementa, al convertirse esta en el factor relativamente más abundante, mientras que los anillos 
más centrales usarán intensivamente el factor trabajo (la relación de factores
$L / T$ será decreciente con la distancia del centro urbano).
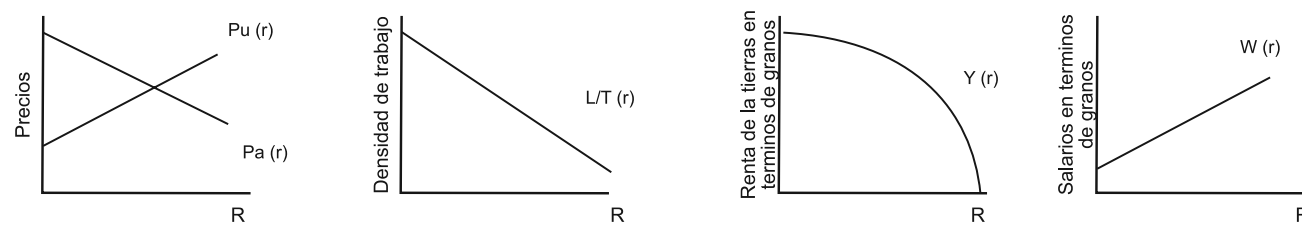

Figura 2. Comportamiento de las variables en el modelo según la distancia.

Fuente: tomado de Samuelson (1983).

En la Figura 2 se representa el funcionamiento de las variables del modelo de localización de acuerdo con la distancia $R$, en la perspectiva del análisis de Samuelson. El primer recuadro representa el hecho de que los precios del bien urbano despachados a una distancia determinada desde la ciudad, deben incrementarse linealmente. Así mismo, el precio del bien agrícola entregado en la ciudad, experimentará una reducción continua en la medida en que la distancia hace que se recorra el anillo exterior. En la tercera ilustración se representa la renta de la tierra en términos de grano, que se comporta en forma decreciente. Si la tierra es un factor inmóvil, la renta relativa de la tierra en términos de grano se reducirá continuamente, con respecto a la renta de los terrenos situados en cercanías de la ciudad. Finalmente, la cuarta ilustración representa los salarios en términos de granos que asumen una tendencia creciente, por cuanto el salario tiene que ajustarse al alza para compensar el mayor precio del bien urbano, conforme la distancia del centro se incrementa.
El modelo expuesto es una obra magistral para asignar el uso de la tierra de modo eficiente y ofrece criterios muy razonables para el funcionamiento de un sistema agrícola, aplicando un sistema de renta diferencial en función de la distancia. Como señaló Samuelson (1983, p. 1481): “... charging competitive land rents is what leads to normative social efficiency".

\section{ASPECTOS METODOLÓGICOS}

Casi todos los fenómenos socioeconómicos se distribuyen de modo desigual en el espacio. Algunos aspectos afectan más intensamente a unos lugares que a otros y las cartografías que representan el simple despliegue de las variables, siempre están matizadas por colores o símbolos que denotan diferencias sobre el plano geográfico. El mérito del análisis espacial consiste en lograr identificar las razones temáticas y los hechos subyacentes que conducen a la diferenciación en el espacio de las variables económicas. 
A efectos del presente análisis, se aplican algunas herramientas muy básicas y estandarizadas de análisis espacial, con el propósito de identificar patrones de localización y señalar por su nombre los municipios que tienen una característica económica y productiva particular. Dado que se pretende abordar el comportamiento espacial de la agricultura, la industria y los servicios, se consideró ilustrativo enfocarse en la identificación de municipios que tuvieran un papel específico en el comportamiento de alguna variable productiva, proponiendo una interpretación a los patrones geográficos desplegados por la herramienta cartográfica.

Como ya se anotó anteriormente, los datos fueron tomados del Instituto Geográfico Agustín Codazzi, cuya consulta está disponible en su página web. Esta información tiene la ventaja de encontrarse a una escala territorial municipal, por lo que se pueden hacer análisis muy al detalle. Sin embargo, como es lógico, no se dispone de todas las variables deseables y por tal motivo se buscaron datos que recogieran de una manera aproximada el fenómeno en cuestión. Así mismo, para facilitar la ubicación cartográfica de las localidades boyacenses, el anexo 1 ofrece el mapa de los municipios y una tabla con sus nombres respectivos. Con respecto al despliegue cartográfico y las herramientas de análisis espacial aplicadas, estas fueron procesadas en el software ArcGIS en su aplicativo Arc MAP 10.1.

La primera herramienta de análisis espacial consiste en la aplicación de hot spot o puntos calientes, en los que se identifican clúster de valores altos o bajos de la variable en vecindades espaciales, caracterizados por agrupamientos de municipios contiguos. Esta técnica es muy útil para señalar con exactitud donde tiene ocurrencia determinado comportamiento de la variable (Universidad Nacional de Colombia, s.f.).

En ocasiones se detecta un alto valor de la variable, pero se puede encontrar aislada del resto de valores altos pertenecientes a otras entidades espaciales. Por tanto, la herramienta busca determinado valor en el contexto de las entidades vecinas. Para conformar un hot spot, el punto debe tener valores altos y encontrarse circundado por entidades que exhiban valores igualmente altos.

Adicionalmente, se ha aplicado un contraste muy difundido en este tipo de análisis, conocido como el índice de autocorrelación espacial de Moran (Ord \& Getis, 1995), cuyo propósito es medir el grado de dependencia espacial de los valores de cada variable entre vecindades, y determinar si existe un patrón espacial que acompañe la distribución de la variable. En efecto, para el análisis espacial es fundamental detectar si las variables siguen un patrón espacial o no, en otras palabras, si la variable se distribuye en forma aleatoria o si los datos conforman un clúster de valores similares en una fracción del plano.

Estos fenómenos de contigüidad espacial pueden atribuirse a la existencia de un 
"efecto contagio", como consecuencia de la vecindad geográfica y por la transmisión de externalidades (Chasco, 2008), cuyo resultado final es el despliegue de un conjunto de entidades espaciales que muestran cierto patrón, agrupando valores altos o valores bajos de la variable en cuestión.

Este fenómeno de autocorrelación espacial puede ser contrastado a través del test de Moran, como lo expone Chasco (2008):

$$
I=\frac{\mathrm{n}}{S_{0}} \frac{\sum_{\mathrm{i}=1}^{\mathrm{n}} \sum_{\mathrm{j}=1}^{\mathrm{n}} \mathrm{W}_{\mathrm{ij}}\left(\mathrm{y}_{\mathrm{i}}-\overline{\mathrm{y}}\right)\left(\mathrm{y}_{\mathrm{j}}-\overline{\mathrm{y}}\right)}{\sum_{\mathrm{i}=1}^{\mathrm{n}}\left(\mathrm{y}_{\mathrm{i}}-\overline{\mathrm{y}}\right)^{2}}
$$

En donde $I$ es el índice de Moran, $\overline{\mathrm{y}_{\mathrm{i}}}$ es el valor de la variable en la locación $\mathrm{i}, \mathrm{y}_{\mathrm{i}}$ es el valor medio de la variable $\mathrm{y}, \mathrm{w}_{\mathrm{ij}}$ representa uno de los elementos de la matriz de ponderaciones espaciales $\mathrm{W}$ y donde $S_{0}$ es un factor de escala equivalente a la sumatoria de todos los elementos de la matriz W. Esta última matriz tiene una orden n, donde $n$ es el número de municipios del departamento (123) que contiene la información de las relaciones de contigüidad entre las observaciones.

La interpretación del índice de Moran se realiza bajo la contrastación de la hipótesis nula de ausencia de autocorrelación espacial. Por tanto, los valores del índice de Moran (I) que arroja la prueba, se interpretan en comparación con los valores que se esperarían en caso de no rechazo de la hipótesis nula, reforzados por los respectivos valores $\mathrm{z}$ y el $\mathrm{p}$ value de la probabilidad (Chasco, s.f.).

Así mismo, el análisis de autocorrelación espacial está acompañado por un reporte en forma de campana de Gauss, con el objeto de observar el contraste de la prueba de hipótesis y si los valores calculados pertenecen al área de aceptación o no de la hipótesis nula. Para el análisis que nos ocupa, el propósito es dilucidar si la distribución espacial de las variables, responde a una distribución aleatoria en el espacio o si se rige por algún patrón de asociación (Universidad Nacional de Colombia, s.f.).

\section{COMPORTAMIENTO ESPACIAL DE LA ECONOMÍA BOYACENSE}

En el modelo de Von Thünen, someramente expuesto en la parte teórica, se destacan varios puntos de interés. La producción exige que en las cercanías a los centros urbanos la tierra sea más eficientemente usada en cultivos más productivos y con tecnologías ahorradoras de dicho factor, mientras que en los lugares más remotos la producción puede ser menos ahorradora en tierra y acoger actividades más extensivas. A mayores distancias del centro urbano, los salarios en términos del bien agrícola tienen que ser reajustados al alza reconociendo que el precio del bien urbano también se incrementa en razón de la distancia, forzando simultáneamente la caída de la renta de la tierra en los anillos más remotos.

Una conclusión resumida del modelo de anillos concéntricos ha sido presentada en 
los siguientes términos: “...el suelo caro cerca del centro estaría reservado para cultivos con costes altos de transporte y/o cultivos que dieran un alto valor por hectárea; el anillo más exterior sería dedicado a cultivos intensivos en tierra o a cosechas de transporte barato" (Krugman, 1995, p. 51).
En lo que sigue se describirá cartográficamente la disposición sobre el plano de algunas variables económicas, haciendo un énfasis particular en las características espaciales de la producción agrícola, contextualizando el desempeño espacial de dicho renglón con respecto a la distribución de otras ramas de actividad.

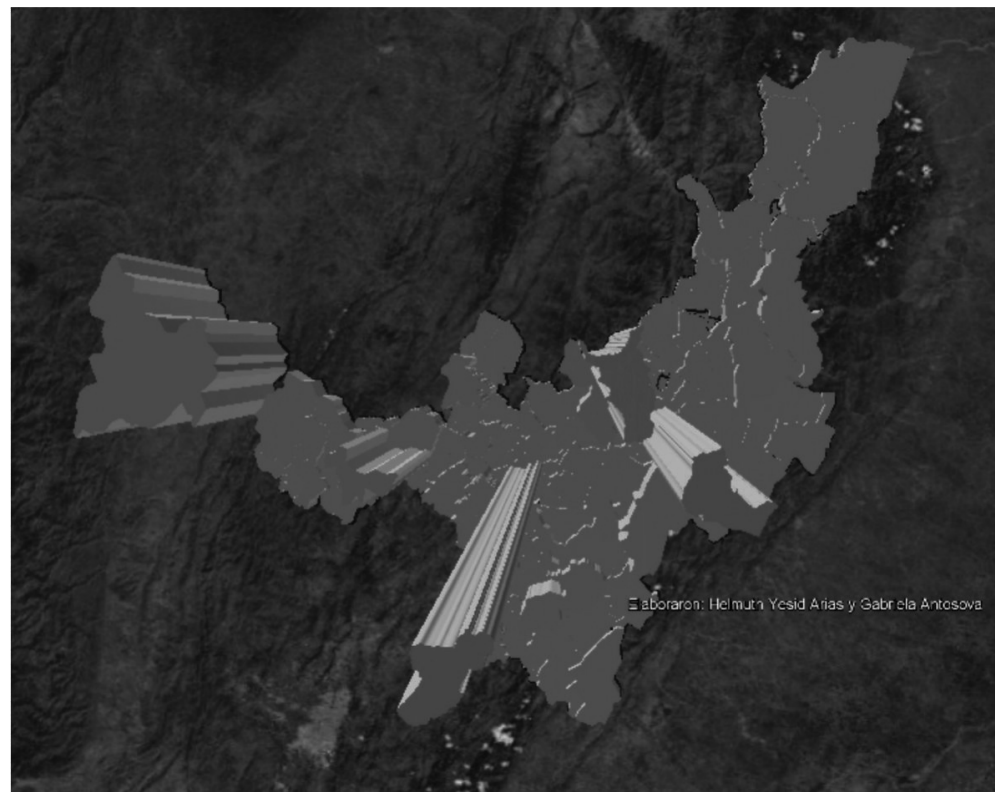

Mapa 1 . Boyacá - Población por municipios

Fuente: elaboración de los autores con datos del sistema SIGOB del IGAC y DANE

El mapa 1 muestra los municipios que concentran la población en el departamento que, al mismo tiempo, fungen como centros urbanos provinciales $y$ que ofrecen un conjunto de servicios económicos irradiados a sus alrededores. La figura más prominente representa a Tunja, la capital, seguida por Sogamoso, Duitama, y Chiquinquirá, esta última ciudad considerada como el centro del mercado de las esmeraldas provenientes de la zona minera y conocida como la capital religiosa de Colombia. También se destacan en el ámbito regional importantes poblaciones como Paipa y Puerto Boyacá.

En este orden de ideas, como lo describen Medina y Bermúdez (2007), Boyacá se caracteriza sociológicamente por un marcado predominio del componente rural 
en su población, por un estancamiento demográfico, y en el plano económico, por la persistencia de predios dominados por la economía campesina de carácter extensivo y con escasa dotación de capital y tecnología. Por su parte, Cruz (2007) identifica ciertas características típicas de las regiones rurales boyacenses con los anillos más periféricos del modelo de Von Thünen, que en la práctica suelen ser menos productivos, con períodos de inactividad de la tierra extensos y con pocos ciclos de cultivo y producción al año.

El departamento continúa mostrando un predominio de la economía campesina con cultivos de subsistencia que involucran a unas 200.000 familias según cálculos aproximados de Medina y Bermúdez (2007), fenómeno que se reconoce en los pequeños poblados y en puntos de movilidad humana campo-ciudad hacia los centros departamentales de Tunja, Sogamoso, Duitama y Chiquinquirá.

En un trabajo reciente, Arias (2011) aplicó la primera etapa de la metodología de distritos industriales para Boyacá, con datos de los movimientos de commuters reportados en el Censo de 2005. Allí se identificaron los municipios que atraían a su mercado laboral trabajadores de otras jurisdicciones, con lo que daban indicios de desempañarse como puntos de atracción en materia laboral, bien por albergar oficinas gubernamentales o entidades judiciales o por constituirse en emplazamientos de una explotación económica bien definida, valga decir, la zona esmeraldífera y algunos municipios turísticos.
Además de los municipios mencionados en el párrafo anterior, aparecen como lugares de atracción de trabajadores Tuta, Cómbita, Samacá, Toca, Soracá, Sora, Chivatá, Cucaita, Garagoa, Chiquinquirá, Saboyá, San Pablo de Borbur, Maripí, Otanche, San Miguel de Sema, Muzo, Villa de Leyva, Sutamarchán, Nobsa, Tibasosa, Firavitoba, Santa Rosa, Paz del Río, Tasco y Socotá, entre otros.

Según lo anterior, el papel que han asumido los distintos municipios refleja el predominio de algunas tendencias recientes en la realidad del departamento, en el sentido de mantener la persistencia de los centros agrícolas y mineros, y la fuerza que han tomado las actividades de servicios, especialmente los servicios gubernamentales.

La estructura económica del departamento reporta algunas novedades recientes. En primer lugar se observa el repunte del sector servicios, fundamentalmente en lo que se refiere a servicios del gobierno y el sector financiero (Rodríguez, 2007). Esta tercerización es un fenómeno propio de la economía contemporánea y que coincide con un retroceso en la participación de la industria y el sector agropecuario.

Algunos municipios muy condicionados por su medio natural carecen de actividades en el sector agropecuario o industrial y se han dedicado a la explotación de la alfarería y el turismo, como es el caso de los diez municipios que hacen intersección con el desierto de la candelaria (Medina \& Bermúdez, 2007). 


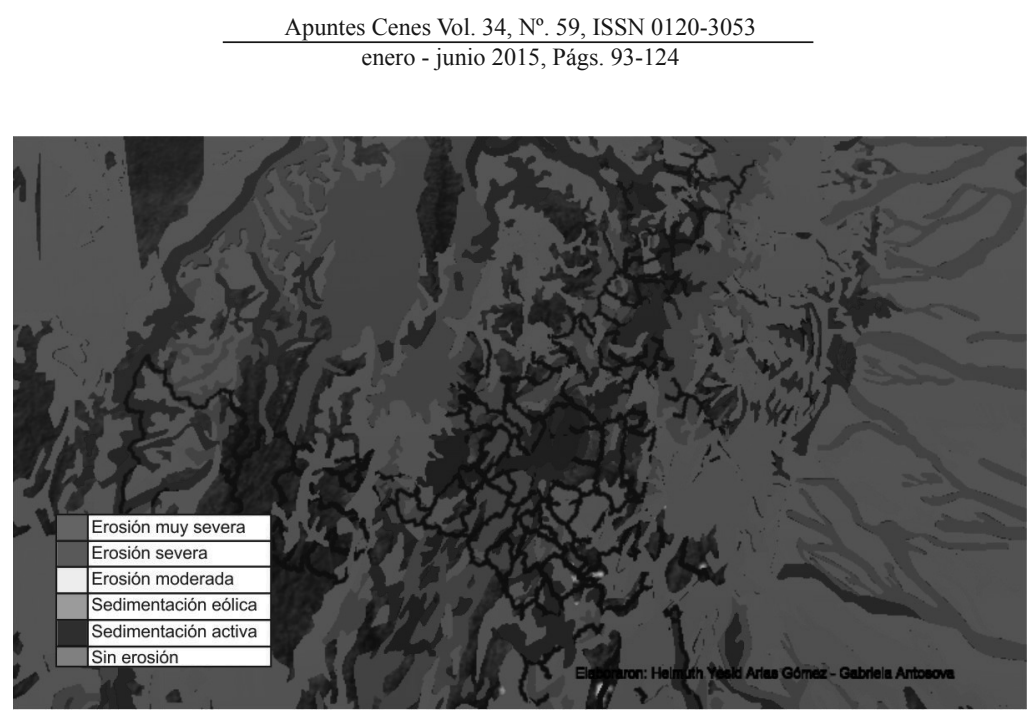

Mapa 2. Boyacá, grado de erosión por municipios

Fuente: elaboración de los autores con datos de IGAC

El mapa 2 representa el estado de la erosión en los municipios y corrobora la influencia del entorno geográfico sobre la producción. La afectación de la erosión del suelo es notoria sobre municipios como Villa de Leiva, Ráquira, Gachantivá, Sotaquirá, Cómbita, entre otros. Se observa también una coloración verde clara en el centro del departamento en suelos muy aptos y que corresponden a una zona muy productiva en términos de producción agrícola. Esta coloración verde con óptima condición productiva incluye los municipios de Samacá, Cucaita, Chíquiza, Tibaná, Turmequé, entre otros. Estas condiciones de fertilidad y el acceso al agua es determinante en la ubicación de cultivos como la papa y la cebolla, de por sí intensiva en agua y tierras húmedas.

Este panorama de los suelos muestra también una zona despejada en el oeste de Boyacá, en la conocida provincia de Occidente, un territorio dedicado a la minería, en concreto a la extracción de esmeraldas. Esta zona esmeraldífera incluye los municipios de Quípama, Maripí, Muzo, Otanche, Coper, Borbur, Coscuez, con una sociología más diversa originada en los movimientos de población proveniente de otras regiones.

Otro centro de producción minera está asociado con la explotación del carbón en los municipios de Samacá, Paz del Río, Socha, Tópaga, Mongua y en las inmediaciones de Sogamoso, cuya producción se encadena con los procesos de siderurgia y la generación de energía termoeléctrica (Medina \& Bermúdez, 2007). En otras localidades, el carbón sirve de insumo para la producción de ladrillo y caliza, particularmente en los municipios de Nobsa, Belencito y las inmediaciones de Sogamoso. 


\section{Agricultura}

En las zonas del departamento donde la tierra es apta, la agricultura es la actividad básica, lo que provoca una alta concentración en algunos productos concretos $\mathrm{y}$ define la especialización productiva del departamento. En este sentido, el Informe de Desarrollo Humano 2011 (PNUD, 2011) identificó cierta estabilidad en las tasas de crecimiento en los departamentos que más participaron en la producción agropecuaria nacional, condición que Boyacá comparte con Antioquia, Valle y Cundinamarca. Los productos que han impulsado el crecimiento sectorial en la región boyacense han sido la papa y el maíz. Adicionalmente, el informe concluye que Boyacá, Santander y Cesar han experimentado cierta evolución al pasar de regiones netamente agrícolas hacia regiones con un repunte de la actividad pecuaria (PNUD, 2011).

Con respecto al desempeño sectorial nacional, el informe del PNUD (2011) destaca el comportamiento de la actividad agropecuaria durante la década de los noventa, periodo en el cual dicho renglón de la producción tuvo un comportamiento procíclico y con tasas de crecimiento cercanas a las de la economía agregada, mientras que años después, el desarrollo del sector fue más mediocre y representó la mitad del crecimiento de la economía como un todo.

Medina y Bermúdez (2007) estiman el número de cabezas de ganado en quinientos mil. La actividad pecuaria se desarrolla en la parte plana que corre paralela a la cordillera Oriental, en un modelo de producción extensiva de tipo latifundista y concentrada, emplazado en los valles de Sotaquirá, Sogamoso, Iza, Belén y Cerinza, y en las inmediaciones de Ventaquemada, Chiquinquirá y Arcabuco. La ganadería también hace presencia hacia el occidente en el área de Puerto Boyacá y en los remotos territorios de Labranzagrande, Pisba y Paya (Medina \& Bermúdez, 2007).

La papa, cultivo emblemático del departamento, se cultiva en zonas altas y frías en la mayoría de casos bajo formas de minifundio en unidades productivas que en promedio abarcan menos de 3 hectáreas por predio, rotándose en dos ciclos productivos al año. Junto con Nariño y Cundinamarca, el departamento de Boyacá encabeza la producción del tubérculo proyectando su mercado a la capital del país, la Costa Atlántica y Bucaramanga (Medina \& Bermúdez, 2007).

La porción de la hoya del río Suárez que se adentra en el departamento de Boyacá se caracteriza por la producción de caña panelera en los municipios de Moniquirá, Togüí, Santana, Chitaraque y San José de Pare. La actividad de la molienda remueve el mercado laboral de su sopor e introduce elementos básicos de un proletariado que se ocupa de la elaboración de la panela. En esta misma comarca, la producción agrícola es mixta, aprovechando simultáneamente cultivos de 
café, yuca, plátano y naranjas (Medina \& Bermúdez, 2007). Como podrá apreciarse más adelante, en el mapa 3 de hot spot agrícola, esta zona aparecerá como un espacio caracterizado por altos valores de producción agrícola particularmente para los cultivos de clima templado.

Los cultivos de la cebolla se instalaron en el departamento bajo dos modalidades. Existe un cultivo comercial productivo en los alrededores de la laguna de Tota y que surte a la capital nacional y otros núcleos urbanos. De otro lado, en pequeñas parcelas la cebolla es cultivada en los municipios de Samacá, Sáchica, Sutamarchán, Tinjacá, Villa de Leiva y las proximidades de la capital del departamento. El cultivo es intensivo en agua y eso explica su ubicación específica en el departamento en cercanías de los cuerpos de agua para facilitar la extracción del líquido para fines productivos.

Las zonas frutales incluyen los municipios de Nuevo Colón, Jenesano, Tibaná, Ramiriquí, Sotaquirá en donde se cultiva durazno, manzana, ciruela, pera, curuba, tomate de árbol, mora, feijoa, entre otros. En el departamento también se produce habichuela, pepino, tomate, cultivos enclavados en las inmediaciones de Guayatá y Somondoco (Medina \& Bermúdez, 2007).

Ahora bien, el análisis subsiguiente se basará en las características espaciales de la producción agrícola. Para tales efectos se aplicará la herramienta del hot spot a los datos de producción agrícola medidos en toneladas, con lo que se pretende señalar zonas bien definidas en el mapa y que demuestran características particulares en materia agrícola.

La representación en el mapa de las zonas con diferentes grados de intensidad de la producción agrícola, da indicios sobre la influencia de las condiciones naturales, geográficas o climáticas que favorecen la explotación de ciertas variedades productivas en jurisdicción de algunos municipios caracterizados por contigüidad espacial. 


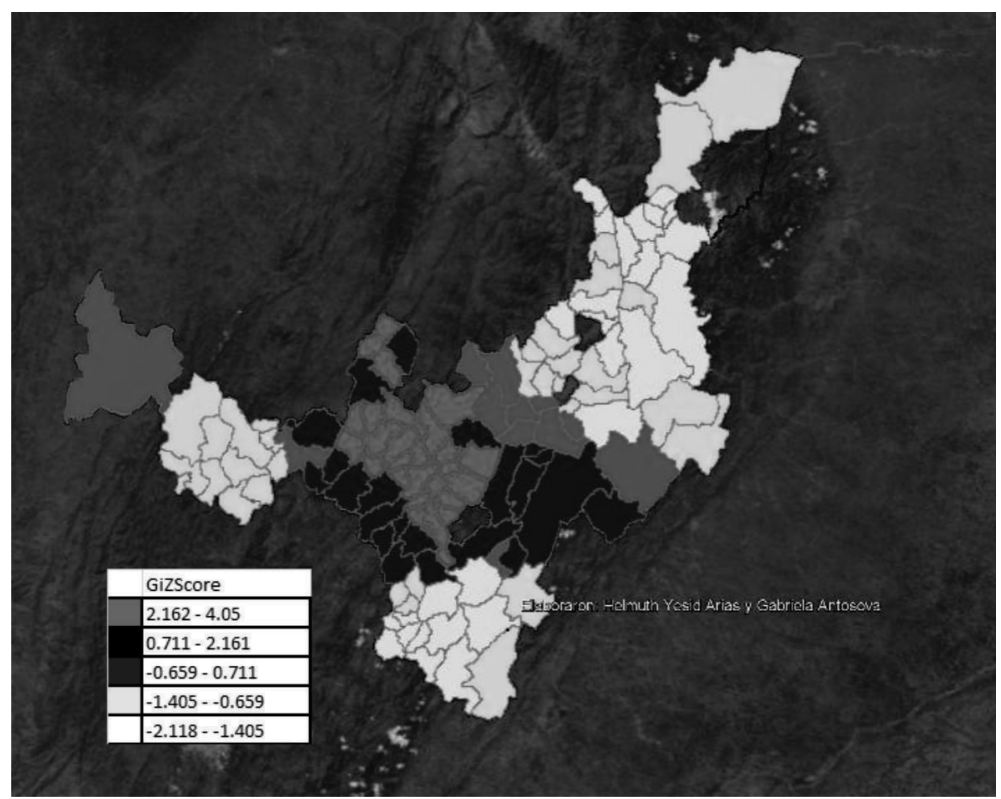

Mapa 3. Boyacá, hot spot de la producción agrícola

Fuente: elaboración de los autores a partir de información del IGAC y Minagricultura

En dichos términos, conviene determinar si una variable económica está correlacionada espacialmente, así como identificar la posible formación de clústers, en cuyo caso la variable puede seguir un patrón espacial, descartando una localización aleatoria (Chasco, s.f.). En lo que sigue, el análisis exige localizar exactamente los municipios en los cuales la producción agrícola exhibe altos valores y adicionalmente definir si las localidades circundantes registran valores de producción similares.

En el mapa 3 se representan los hot spots de la producción agrícola, es decir, conjuntos de municipios con valores similares de la variable y según los cuales se perfilan zonas del departamento bien definidas.

Allí aparecen en color rojo los municipios con elevados valores conformando un clúster central de tierras frías, en donde cumplen un importante papel de los cultivos de papa, alverja y pastos. Esta zona bastante productiva se extiende por los municipios de Ramiriquí, Chivatá, Jenesano, Viracachá, Cucaita, Chíquiza, Sáchica, Toca, Oicatá, Sotaquirá, Sutamarchán, Santa Sofía, Gachantivá, Arcabuco, Cómbita, Motavita y la capital del departamento, Tunja. Sin embargo, sin contigüidad espacial, más al norte se perfilan tres municipios de alta 
producción agrícola como Chitaraque, Santana y San José de Pare.

Debajo de este primer grupo, la producción agrícola se distribuye con menores valores en un anillo que rodea al grupo principal y que se marca en color negro. Los municipios allí incluidos se especializan en la producción de cebolla, y algunos de ellos sobresalen más en la producción minera o en la artesanía. Este grupo en forma de circunferencia lo constituyen los municipios de Pajarito, Aquitania, Tota, Pesca, Zetaquira, Tibaná, Úmbita, Turmequé, Nuevo Colón, Ventaquemada, Samacá, Ráquira, Tinjacá, San Miguel de Sema, entre otros.

En un grupo intermedio de producción agrícola entran a jugar poblaciones con predominio de actividad urbana e industrial y otros municipios más alejados del centro del departamento. En color azul aparecen marcados los municipios de Duitama, Paipa, Sogamoso, Chiquinquirá, Labranzagrande, Nobsa, Tibasosa, Mongüi, y aparece también en el occidente, Puerto Boyacá.

Finalmente, se presentan dos grupos con menor producción agrícola con dos características típicas destacadas por la geografía económica para la localización de la producción: la ventaja natural y los costos de transporte y la distancia.

En color amarillo se dibuja una serie de municipios ubicados en el occidente de Boyacá, los cuales sobresalen más por su producción minera que por la agrícola. Otros están afectados por una precaria comunicación por vía terrestre, mientras que otros están ubicados en lugares más centrales. En este grupo los municipios esmeraldeños son Otanche, Quípama, San Pedro de Borbur, Muzo y Pauna. Junto a ellos aparece Buenavista, Caldas, Tununguá y en el norte se incluyen Chiscas y Cubará. Más al centro del departamento se ubican Belén, Beteitiva, Tasco, Floresta, Gámeza, Tópaga, Santa Rosa y Cerinza.

El grupo con menor importancia en la producción agrícola está condicionado por la distancia con respecto a los centros de mercado y marca claramente un esquema periférico en la geografía del departamento. Allí aparecen Miraflores, Macanal, Santa María, Chivor, Guayatá, Garagoa y Campo Hermoso. En el norte se dibujan Chita, Guacamayas, El Espino, Tipacoque, La Uvita, Sativanorte, Tutaza, Socha, entre otros. 


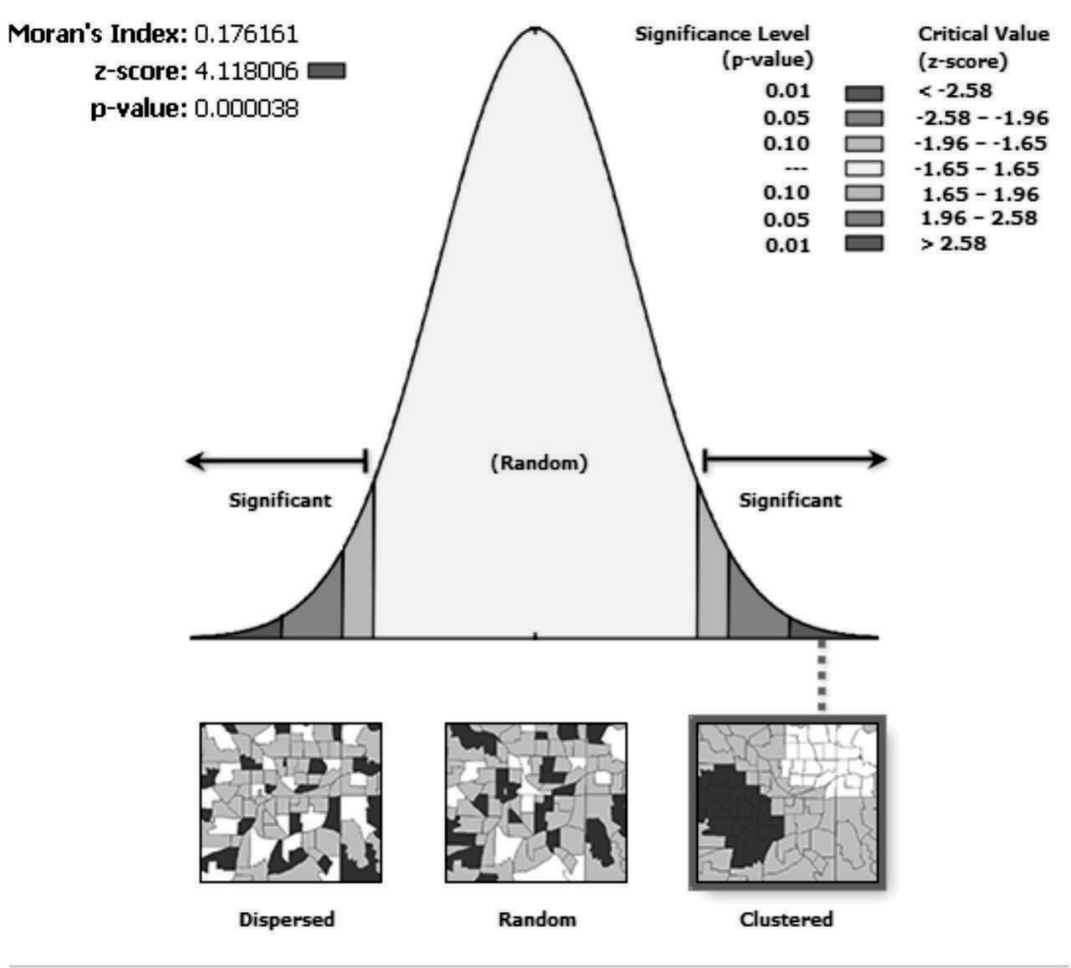

Given the $z$-score of 4.12 , there is a less than $1 \%$ likelihood that this clustered pattern could be the result of random chance.

Figura 3. Índice de Moran de la producción agrícola

Fuente: resultado de herramienta aplicada en el software ArcGis

Los fenómenos espaciales implican que unidades contiguas o cercanas posean valores similares y que a medida que las observaciones se alejan en el espacio, dichos valores se van haciendo más disímiles. A través del concepto de autocorrelación espacial se evalúa si las jurisdicciones cercanas entre sí tienen valores parecidos. Para tal efecto se interpretará un indicador estándar para detectar la autocorrelación espacial, conocido como el índice de Moran (Ord \& Getis, 1995; Chasco, 2008).
Observando la Figura 3, según el índice de Moran, su Zscore y el p value, se rechaza la hipótesis nula de distribución aleatoria, dando indicio de la definición de un patrón espacial de la producción agrícola. Adicionalmente, el reporte gráfico ubica el Zscore de 4,11 en la cola derecha de la campana de Gauss, de modo que se confirma que los valores siguen un patrón de tipo clúster. Por tanto, se puede afirmar que los datos de producción agrícola exhiben autocorrelación espacial y que se conforman aglomeraciones de 
tipo clúster observando la distribución por municipios de la variable en cuestión.

En efecto, considerando la vocación agrícola del departamento es muy posible que las condiciones naturales y climáticas favorezcan un tipo de producción muy similar entre municipios vecinos. Esto se corresponde con el papel destacado de esta sección del país en materia de producción de la papa, la cebolla, frutales, entre otros.

\section{Industria}

La industria manufacturera en Boyacá se ha caracterizado por ser poco diversificada para los estándares de otras secciones del país. Adicionalmente está muy limitada a la existencia de ciertas agrupaciones específicas y, por lo general, responde a fuertes encadenamientos con los recursos naturales, con una marcada presencia de la agroindustria. En la Tabla 1 aparecen las agrupaciones industriales más importantes que hacen presencia en el departamento, consultando los datos de la Encuesta Anual Manufacturera del DANE.

En Boyacá, la industria manufacturera se ha instalado en localizaciones específicas dando origen a ciudadelas industriales y propiciando economías de aglomeración. En las inmediaciones de Duitama y Sogamoso se han emplazado establecimientos de fabricación de carrocerías y otro material de transporte, que han definido un perfil industrial en dichos municipios. Desde el año de 1958, el departamento ha acogido en el municipio de Nobsa a la empresa Acerías Paz del Río, la cual satisface el $30 \%$ del mercado de acero en el país y se ha constituido en un establecimiento emblemático de la región. Mención adicional debe hacerse también de la empresa que lleva por nombre Siderúrgica de Boyacá.

De importancia para el departamento son la planta de fabricación de cerveza en Tibasosa y los establecimientos de bebidas en la ciudad de Duitama. La agrupación de minerales no metálicos participa con una planta de cementos en el municipio de Nobsa y con una serie de fábricas de diversos tamaños dedicadas a la elaboración de baldosas y ladrillos a lo largo y ancho del departamento. Célebre es el caso de la antigua fábrica textil de Samacá, que ha sufrido muchos vaivenes en su historia y cuyo origen se remonta al siglo XIX.

Tabla 1. Boyacá. Participación de cada agrupación en el empleo manufacturero departamental 2009 (\%)

\begin{tabular}{|c|c|c|c|c|c|c|c|c|c|}
\hline $\begin{array}{c}\text { Alim. } \\
\text { Beb. }\end{array}$ & Textil & Confección & Química & Caucho & $\begin{array}{c}\text { No } \\
\text { metálicos } \\
\text { y vidrio }\end{array}$ & $\begin{array}{c}\text { Metalurgía } \\
\text { básica }\end{array}$ & $\begin{array}{c}\text { Minerales } \\
\text { metálicos }\end{array}$ & $\begin{array}{c}\text { Vehíc. } \\
\text { Remolqu. }\end{array}$ & $\begin{array}{c}\text { Muebles } \\
\text { y otros }\end{array}$ \\
\hline 13,3 & 0,9 & 2,0 & 1,4 & 0,4 & 13,8 & 48,6 & 5,3 & 3,2 & 1,5 \\
\hline
\end{tabular}

No aparecen todas las agrupaciones y no necesariamente suma 100 .

Fuente: cálculos propios con base en EAM. 
Sin embargo, la actividad industrial más generalizada es la relacionada con la agrupación de alimentos y bebidas que hace presencia en muchos municipios del departamento y que responde a la arraigada vocación agropecuaria de Boyacá.

En el mapa 4 se observa que el mayor número de establecimientos industriales se localizan en la zona industrial ubicada en los alrededores de Duitama, incluyendo los municipios de Nobsa, Firavitoba, Santa Rosa y Paipa, conformando un clúster industrial característico en la región.

Un segundo grupo de municipios marcados en color negro, aparecen como zonas industriales de menor intensidad incluyendo los municipios de Sogamoso y Aquitania y más hacia el centro del departamento se dibuja un anillo en los alrededores de Tunja.

Un tercer grupo con coloración azul abarca los municipios de la hoya del río Suárez, así como San Miguel de Sema, Sáchica, Sutamarchán, entre otros.

Otras regiones albergan un menor número de establecimientos industriales y se localizan en los extremos periféricos del departamento. Allí aparecen municipios de la zona occidental del departamento y de las provincias de Valderrama, Gutiérrez, Neira y La Libertad.

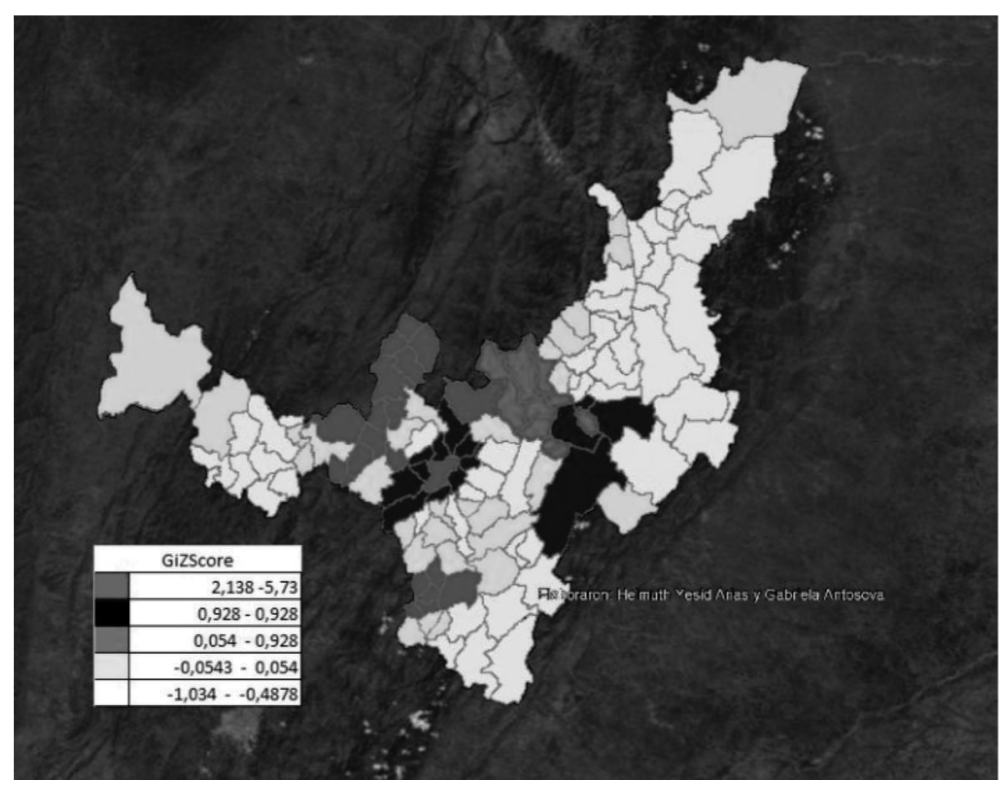

Mapa 4. Boyacá, hot spot de las unidades industriales por municipio Fuente: elaboración de los autores a partir de información del IGAC y DANE 
Si se habla en términos espaciales, la industria en Boyacá está concentrada en los municipios más urbanizados. Las localidades que rodean a la ciudad de Duitama han conformado un anillo industrial de menor intensidad, lo mismo que otros municipios de tamaño mediano, especialmente en la hoya del río Suárez. Finalmente, en la periferia del departamento, la industria se limita a un reducido número de unidades industriales con escasa influencia sobre la economía local.

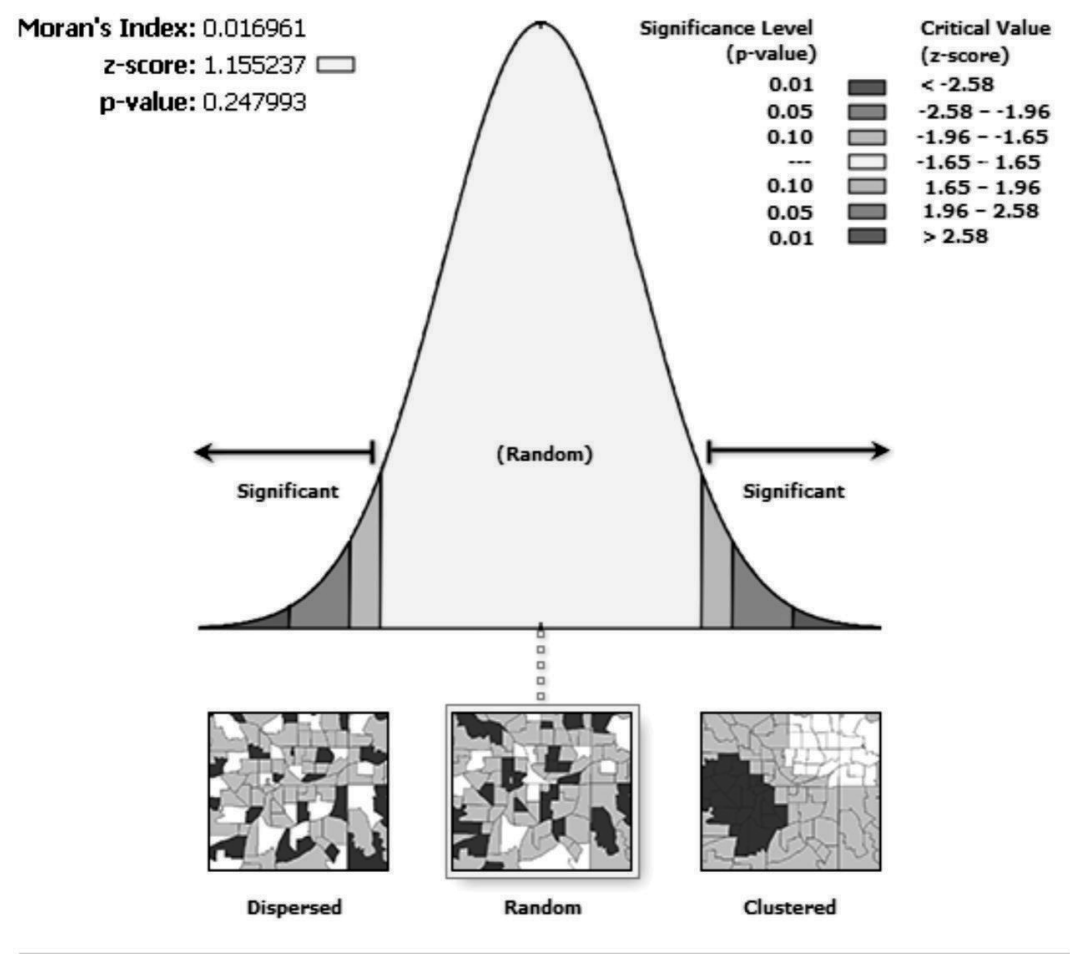

Given the $z$-score of 1.16 , the pattern does not appear to be significantly different than random.

Figura 5. Índice de Moran del número de unidades industriales

Fuente: resultado de herramienta aplicada en el software ArcGis

Según la Figura 5, el análisis de autocorrelación espacial para la variable número de unidades industriales, está acompañado por un valor de probabilidad que no permite rechazar la hipótesis nula de distribución aleatoria de las unidades industriales en el espacio, e igualmente el índice de Moran (I) es lo suficientemente bajo para aproximarse al valor esperado en caso de no rechazo de la hipótesis nula. 
Esto permite concluir que la variable en cuestión se distribuye de forma aleatoria en el espacio y que municipios vecinos no guardan una relación estrecha entre sí, en cuanto al número de establecimientos industriales. Esto se comprende mejor si se tiene en cuenta el predominio de las actividades agrícolas, mas no industriales, en la mayoría de municipios. Igualmente se refuerza el carácter de enclave de las actividades manufactureras que comúnmente se hallan instaladas en inmediaciones de yacimientos minerales, como es el caso de la industria siderúrgica.

\section{El sector de servicios}

En los últimos años, la economía boyacense experimentó una tercerización paulatina ante la expansión tanto de los servicios del gobierno, como de los servicios de mercado, en detrimento de las ramas tradicionales de actividad. Rodríguez (2007) insiste en la pérdida de participación del sector primario en el departamento, frente al creciente protagonismo del sector terciario, que para 2004 ya representaba el $53 \%$ del PIB boyacense. En referencia al dato nacional, el informe del PNUD (2011) reconoce también un retroceso en la participación del sector agropecuario en el total de la producción como un fenómeno generalizado a nivel internacional, con el agravante de que en el caso colombiano se haya registrado un acusado declive en el crecimiento de la productividad sectorial y de la competitividad.

Con respecto a las actividades terciarias, se construyó una representación cartográ- fica de los emplazamientos del sector de servicios de mercado en los que se incluyen servicios de comercio, profesionales, hoteleros y de restaurantes, entre otros, según la información que es capturada por el DANE y que se puede consultar en la información georreferenciada del IGAC. En el mapa 5 de hot spot, se describe una tendencia muy lógica de la localización de los servicios en el departamento, condicionada por los mercados de las poblaciones con características más urbanas, a saber: Tunja y Duitama, en anillos que aparecen marcados en color rojo.

El fenómeno es más evidente en torno a la ciudad de Duitama, porque se detectó importante actividad terciaria en los municipios de Santa Rosa, Iza, Belén, Floresta, Firavitoba y Paipa. Esto puede señalar que muchos proveedores del sector servicios gravitan en torno a municipios con características de ciudad, sin que necesariamente operen radicados en las áreas más urbanas. Esto puede dar un indicio de movimientos de commuters que prestan servicios a clientes ubicados en otras jurisdicciones (Arias, 2011).

Sogamoso aparece en un segundo grupo marcado en color negro junto con otros municipios en donde se detectó actividad de servicios como en Aquitania, Mongua y Corrales. De este segundo grupo de municipios también hacen parte Villa de Leyva, con actividades centradas en el turismo, así como Soatá, Miraflores, Garagoa, Muzo, Santa Sofía, entre otros. 


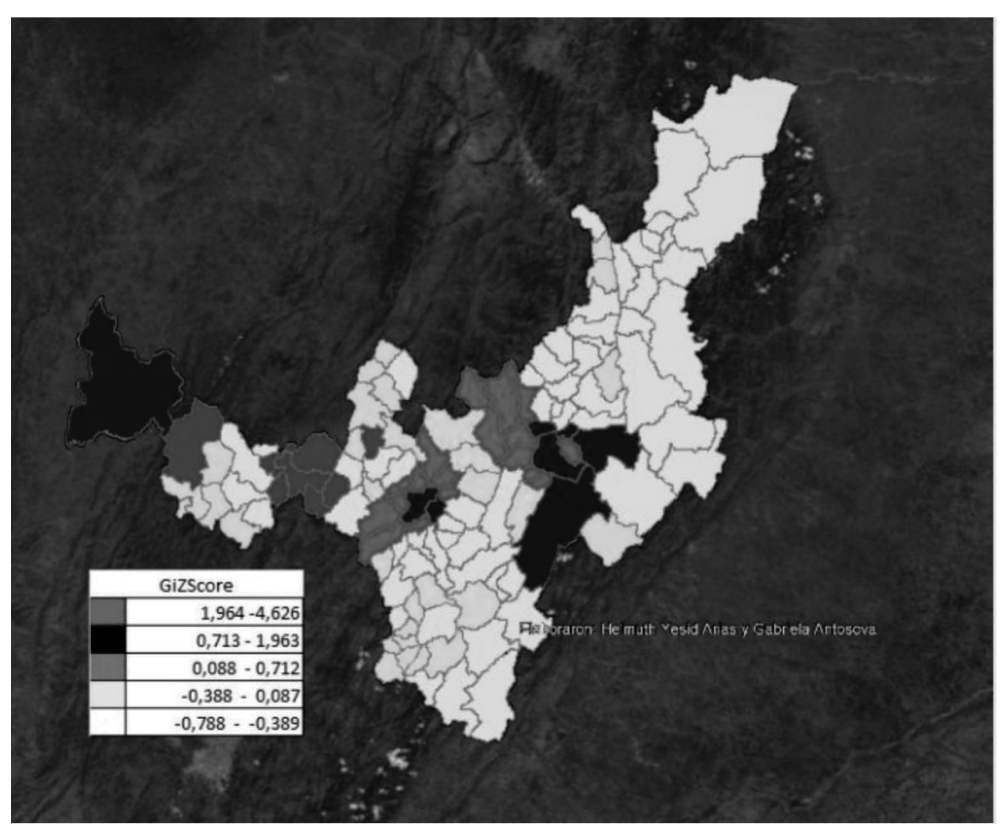

Mapa 5. Boyacá, hot spot de las unidades de servicios por municipio Fuente: elaboración de los autores a partir de información del IGAC y DANE

Sin embargo, por el predominio de los colores amarillo y blanco, existe muy poca actividad del sector servicios en la mayoría de municipios del departamento, comprendiendo las provincias de Gutiérrez, Valderrama, Neira, algunos municipios del centro del departamento y en la zona esmeraldífera.

De la distribución espacial del sector servicios se puede concluir que el grueso de la actividad se concentra en las principales áreas urbanas. Sin embargo, se han constituido anillos de menor intensidad en los municipios aledaños a las ciudades importantes del departamento, lo que hace pensar en un efecto de irradiación desde municipios con actividad urbana hacia sus vecindades. Es fácil suponer este tipo de influencia hacia las áreas circunvecinas: el transporte, el comercio, los servicios profesionales y las actividades de los commuters crean vínculos económicos entre localidades.

Otro aspecto por destacar es la precaria actividad de servicios en amplias comarcas del departamento, particularmente las más alejadas del centro, fenómeno explicado por la carencia de capital humano, la escasa comunicación y la fuerte especialización en actividades estancadas que operan sin encadenamientos hacia otros sectores. 


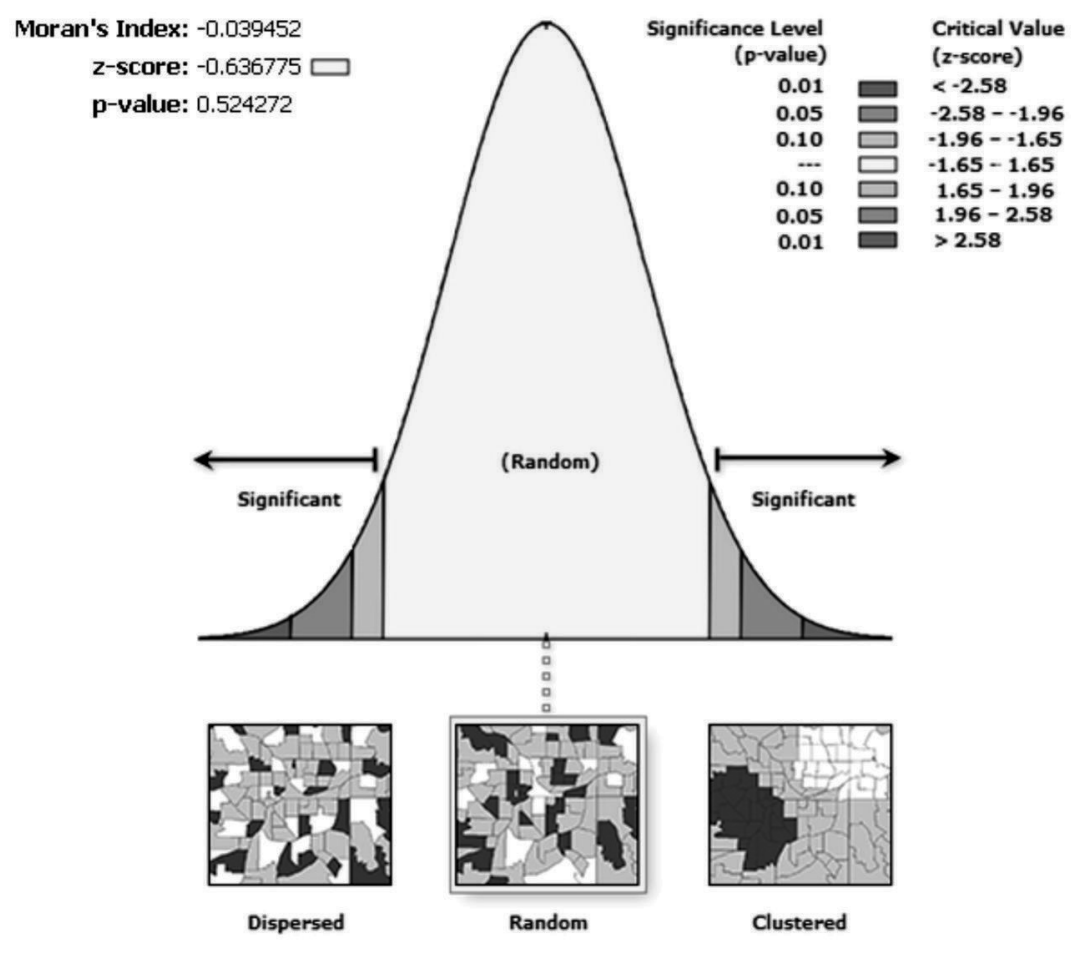

Given the $z$-score of -0.64 , the pattern does not appear to be significantly different than random.

Figura 6. Índice de Moran del número de unidades de servicios

Fuente: resultado de herramienta aplicada en el software ArcGis

De acuerdo con la Figura 6, en el caso de la variable número de unidades de servicios, el índice de Moran no da indicios de rechazar la hipótesis nula de distribución aleatoria de la variable en el espacio (Chasco, s.f.; Chasco, 2008). La concentración de establecimientos de servicios en las áreas más urbanas y la escasa presencia de estos en los poblados de la periferia conforman un panorama de reducida autocorrelación espacial de la variable.

\section{CONCLUSIONES}

La distribución espacial de la actividad económica en Boyacá revela una cartografía de especialización interesante, que coincide con una percepción a primera vista. En las ciudades más importantes del departamento predominan las actividades industriales y de servicios, que son ramas de actividad que se complementan adecuadamente, reforzadas por el tamaño de los mercados urbanos. Existe una región geográficamente 
central, altamente productiva en términos de bienes agrícolas dominada por cultivos de tierra fría, secundada en los alrededores de Moniquirá por una buena producción de clima templado. El occidente se caracteriza por el énfasis en la producción minera que aprovecha su ventaja comparativa y eclipsa la producción agrícola. Finalmente, las periferias del departamento tienen un predominio de actividades agrícolas pero con precarios desempeños en términos de productividad.

Esto se ve corroborado en el ejercicio de hot spot de la producción agrícola que definió muy claramente algunas zonas de explotación. Una comarca muy productiva en torno al cultivo de la papa y otros productos de tierra fría se identificó en la provincia de Centro y en algunos municipios de la provincia de Márquez. Más al norte, otra zona altamente productiva es la hoya del río Suárez. Un segundo anillo con menos intensidad de la producción agrícola, se conformó alrededor de la primera zona abarcando algunos municipios de las provincias de Sugamuxi y de Márquez. Los territorios más periféricos del departamento y la zona predominantemente minera, reflejaron una menor intensidad de la producción agrícola.

Los resultados de los contrastes de autocorrelación espacial revelan características diferentes en las actividades económicas. En el caso de la producción agrícola se detectaron altos grados de correlación espacial, lo que se puede explicar por la ventaja natural que tienen municipios contiguos en la explotación de productos concretos de origen agrícola. Esto indica que los valores de la producción entre poblaciones vecinas reflejan similitudes y permiten visualizar como clústers grupos de municipios que se aglomeran espacialmente. Situación explicable, porque los municipios contiguos pueden compartir condiciones geográficas y climáticas comunes que los convierten en lugares propicios para el cultivo de ciertos productos y con similares características de productividad.

Por el contrario, en el caso del número de unidades industriales por municipios, existe escasa correlación espacial porque la producción manufacturera tiene características de enclave, sin efectos de arrastre espacial a las vecindades y porque depende del acceso a recursos naturales, los cuales se distribuyen aleatoriamente en el territorio. Por tanto, se puede afirmar que dicha variable responde a un esquema de tipo aleatorio y no sigue un patrón de similitud con respecto a las vecindades.

Igualmente, el número de unidades de servicios no demuestra tener una autocorrelación espacial clara entre municipios vecinos, porque se observa que el grueso de dicha actividad se limita a las ciudades más grandes, aunque una excepción puede hacerse al observar el anillo que sobresale en las vecindades de Duitama.

Elanálisis de la especialización económica de los municipios del departamento encuentra inspiración en distintos enfoques teóricos. 
El principio de la ventaja comparativa puede explicar una respuesta espontánea de la economía a los condicionamientos climáticos, naturales y de suelo, como se puede observar en el mapa de la erosión en el departamento. Según el modelo de Von Thünen, los criterios de eficiencia conducen a un uso racional del suelo, que localizan los cultivos relativamente más productivos y ahorradores de tierra en cercanías al centro urbano, mientras que en los lugares más alejados se pueden desarrollar actividades intensivas en el recurso tierra cultivable.

En resumen, la producción económica departamental se ha configurado espacialmente en torno a lugares centrales que tienen un marcado predominio de la actividad agrícola y una presencia destacada de las unidades de servicios. Por otra parte, existen unas regiones periféricas muy incomunicadas, con una precaria infraestructura y con el predominio de estructuras productivas de minifundio, que lastran la productividad de la economía municipal.

El atraso económico y el aislamiento geográfico generan una serie de dinámicas que se retroalimentan. En efecto, se observa que en los lugares más centrales y en sus anillos circundantes, existe alta presencia de actividades industriales, agrícolas y de servicios. Al mismo tiempo, los municipios más periféricos están desprovistos de variedad productiva y se caracterizan por una reducida presencia del sector de servicios y de las actividades industriales. Es decir, si no existe un sector económico dinámico, no se originan encadenamientos con otras actividades productivas que diversifiquen la economía local. Así mismo, los altos costos de transporte que se derivan del aislamiento, ocasionan pérdida de productividad e impiden que los encadenamientos interrama se desarrollen adecuadamente.

Es interesante percatarse de que Duitama ha configurado un área de influencia claramente apreciable si se compara con la influencia espacial de otras ciudades del departamento, particularmente por la presencia de unidades industriales y de servicios en los municipios que la circundan, lo que corrobora una relativa similitud en las magnitudes y las actividades desplegadas en dicha ciudad con respecto a sus áreas adyacentes.

\section{REFERENCIAS}

1. Arias, H. (2011). Aglomeración económica y sistemas locales de trabajo. Apuntes del CENES, 30 (51), 9-43.

2. Cabral D. (2011). Von Thünen e o abastecimento madeireiro de centros urbanos prè industriais. Revista Brasileira de Estudos de População, 28 (2), 405-427. 
3. Chasco, C. (s. f.). Métodos gráficos del análisis exploratorio de datos espaciales. Madrid: Universidad Autónoma de Madrid.

4. Chasco, C. (2008). Geografía y precios de la vivienda en los municipios de España. Revista Económica de Castilla la Mancha, 12, 242-272.

5. Cruz, J. (2007). La vigencia del modelo de Von Thünen. En E. Rodríguez \& L. Vallejo (comp.). Modelos de desarrollo y economía regional. Tunja: Uptc, Facultad de Ciencias Económicas.

6. Departamento Administrativo Nacional de Estadística DANE. (2014). Estadísticas por tema. Bogotá. Recuperado de: www.dane.gov.co

7. Fujita, M. et al. (2000). Economía espacial. Las ciudades las regiones y el comercio internacional. Barcelona: Ariel.

8. Instituto Geográfico Agustín Codazzi, IGAC. (2014). Sistema de información geográfica para la planeación y el ordenamiento territorial. Bogotá: IGAC. Recuperado de: http:// sigotn.igac.gov.co/sigotn/

9. Krugman, P. (1992). Geografia y comercio. Barcelona: Antoni Bosch.

10. Krugman, P. (1995), Desarrollo geografía y teoría económica. Barcelona: Antoni Bosch.

11. Marshall, A. (2005). Principios de economía. Madrid: Fundación ICO, Editorial Síntesis.

12. Medina, R. \& Bermúdez, J. (2007). Planeación del desarrollo regional: una mirada política en medio del conflicto. En E. Rodríguez \& L. Vallejo (comp.). Modelos de desarrollo y economía regional. Tunja: Uptc, Facultad de Ciencias Económicas.

13. Ord, J.K. \& Getis, A. (1995). Local spatial autocorrelation statistics: distributional issues and an application. Geographical Analysis, 27(4), 286-306.

14. PNUD (2011). Colombia rural: razones para la esperanza. Informe nacional de desarrollo 2011. Bogotá: PNUD.

15. Rodríguez, E. (2007) Los contornos de la economía departamental en las últimas dos décadas. En E. Rodríguez \& L. Vallejo (comp.). Modelos de desarrollo y economía regional. Tunja: Uptc, Facultad de Ciencias Económicas.

16. Samuelson, P. (1983). Thünen at two hundred. Journal of Economic Literature, 21, 14681488.

17. Universidad Nacional de Colombia. (s.f.). Visualización en $3 D$ y creación de mapas con ArcGIS. Laboratorio de Tecnologías de Información Geográfica. Bogotá: Departamento de Geografía Unal. 


\section{ANEXO 1}

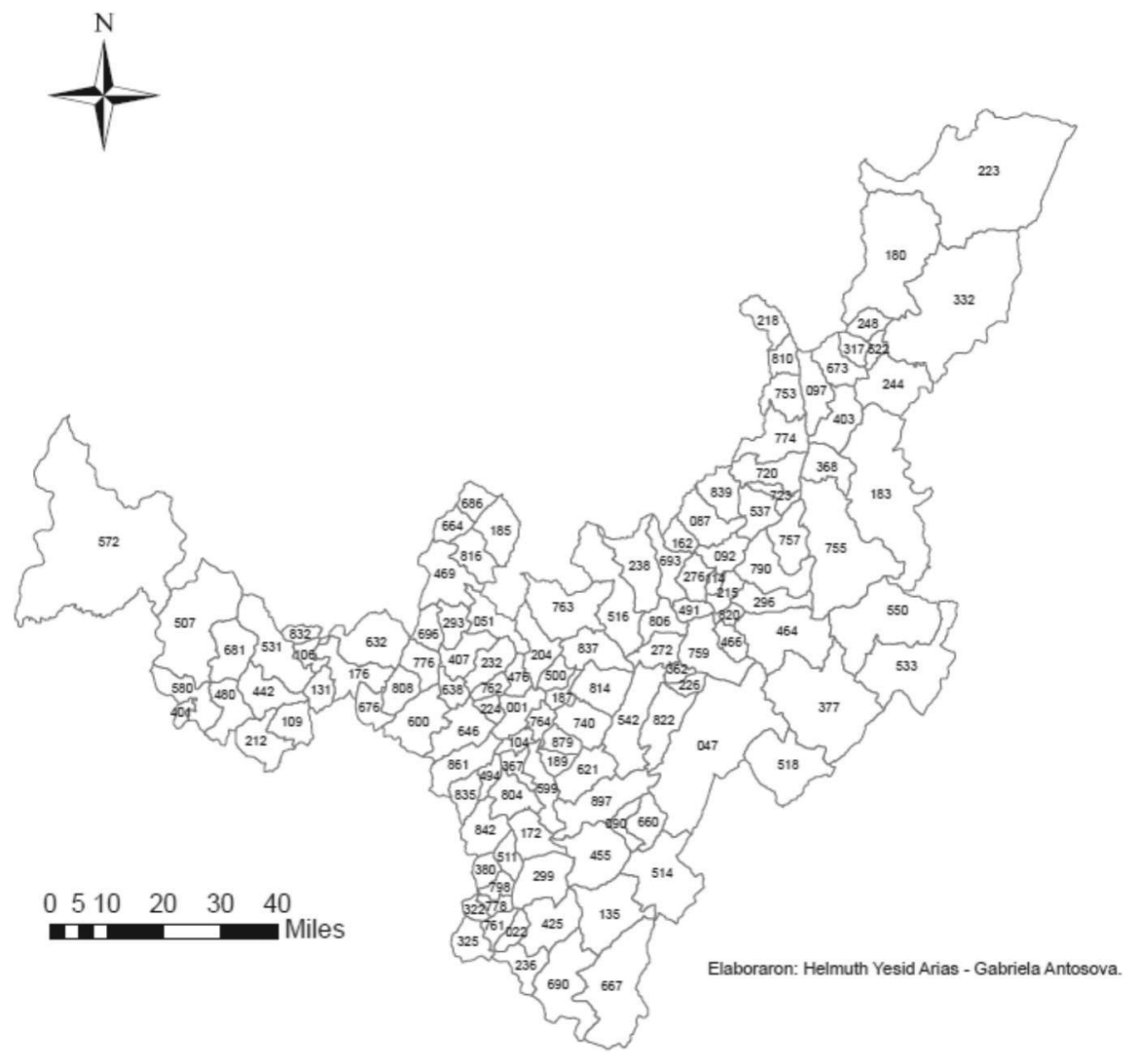

Mapa 6. Boyacá: división político-administrativa

Fuente: IGAC, DANE 


\begin{tabular}{|c|c|c|c|c|c|}
\hline $\begin{array}{l}\text { Código } \\
\text { Depto. }\end{array}$ & $\begin{array}{c}\text { Código } \\
\text { Municipio }\end{array}$ & Nombre & $\begin{array}{l}\text { Código } \\
\text { Depto. }\end{array}$ & $\begin{array}{c}\text { Código } \\
\text { Municipio }\end{array}$ & Nombre \\
\hline 15 & 1 & Tunja & 15 & 238 & Duitama \\
\hline 15 & 22 & Almeida & 15 & 244 & El Cocuy \\
\hline 15 & 47 & Aquitania & 15 & 248 & El Espino \\
\hline 15 & 51 & Arcabuco & 15 & 272 & Firavitoba \\
\hline 15 & 87 & Belén & 15 & 276 & Floresta \\
\hline 15 & 90 & Berbeo & 15 & 293 & Gachantivá \\
\hline 15 & 92 & Beteitiva & 15 & 296 & Gámeza \\
\hline 15 & 97 & Boavita & 15 & 299 & Garagoa \\
\hline 15 & 104 & Boyacá & 15 & 317 & Guacamayas \\
\hline 15 & 106 & Briceño & 15 & 322 & Guateque \\
\hline 15 & 109 & Buenavista & 15 & 325 & Guayatá \\
\hline 15 & 114 & Busbanzá & 15 & 332 & Guicán \\
\hline 15 & 131 & Caldas & 15 & 362 & Iza \\
\hline 15 & 135 & Campohermoso & 15 & 367 & Jenesano \\
\hline 15 & 162 & Cerinza & 15 & 368 & Jericó \\
\hline 15 & 172 & Chinavita & 15 & 377 & Labranzagrande \\
\hline 15 & 176 & Chiquinquirá & 15 & 380 & La Capilla \\
\hline 15 & 180 & Chiscas & 15 & 401 & La Victoria \\
\hline 15 & 183 & Chita & 15 & 403 & La Uvita \\
\hline 15 & 185 & Chitaraque & 15 & 407 & Villa de Leyva \\
\hline 15 & 187 & Chivata & 15 & 425 & Macanal \\
\hline 15 & 189 & Cienega & 15 & 442 & Maripi \\
\hline 15 & 204 & Cómbita & 15 & 455 & Miraflores \\
\hline 15 & 212 & Coper & 15 & 464 & Mongua \\
\hline 15 & 215 & Corrales & 15 & 466 & Mongui \\
\hline 15 & 218 & Covarachía & 15 & 469 & Moniquirá \\
\hline 15 & 223 & Cubará & 15 & 476 & Motavita \\
\hline 15 & 224 & Cucaita & 15 & 480 & Muzo \\
\hline 15 & 226 & Cuitiva & 15 & 491 & Nobsa \\
\hline 15 & 232 & Chíquiza & 15 & 494 & Nuevo Colon \\
\hline 15 & 236 & Chivor & 15 & 500 & Oicatá \\
\hline 15 & 507 & Otanche & 15 & 740 & Siachoque \\
\hline 15 & 511 & Pachavita & 15 & 753 & Soata \\
\hline 15 & 514 & Páez & 15 & 755 & Socotá \\
\hline 15 & 516 & Paipa & 15 & 757 & Socha \\
\hline 15 & 518 & Pajarito & 15 & 759 & Sogamoso \\
\hline 15 & 522 & Panqueba & 15 & 761 & Somondoco \\
\hline 15 & 531 & Pauna & 15 & 762 & Sora \\
\hline 15 & 533 & Paya & 15 & 763 & Sotaquirá \\
\hline 15 & 537 & Paz de Rio & 15 & 764 & Soracá \\
\hline
\end{tabular}


Perfil espacial de la economía boyacense

Helmuth Yesid Arias Gómez - Gabriela Antošová

\begin{tabular}{|c|c|c|c|c|c|}
\hline $\begin{array}{l}\text { Código } \\
\text { Depto. }\end{array}$ & $\begin{array}{c}\text { Código } \\
\text { Municipio }\end{array}$ & Nombre & $\begin{array}{l}\text { Código } \\
\text { Depto. }\end{array}$ & $\begin{array}{c}\text { Código } \\
\text { Municipio }\end{array}$ & Nombre \\
\hline 15 & 542 & Pesca & 15 & 774 & Susacon \\
\hline 15 & 550 & Pisva & 15 & 776 & Sutamarchán \\
\hline 15 & 572 & Puerto Boyacá & 15 & 778 & Sutatenza \\
\hline 15 & 580 & Quípama & 15 & 790 & Tasco \\
\hline 15 & 599 & Ramiriquí & 15 & 798 & Tenza \\
\hline 15 & 600 & Ráquira & 15 & 804 & Tibaná \\
\hline 15 & 621 & Rondon & 15 & 806 & Tibasosa \\
\hline 15 & 632 & Saboya & 15 & 808 & Tinjacá \\
\hline 15 & 638 & Sachica & 15 & 810 & Tipacoque \\
\hline 15 & 646 & Samacá & 15 & 814 & Toca \\
\hline 15 & 660 & San Eduardo & 15 & 816 & Togüi \\
\hline 15 & 664 & San Jose de Pare & 15 & 820 & Tópaga \\
\hline 15 & 667 & San Luis de Gaceno & 15 & 822 & Tota \\
\hline 15 & 673 & San Mateo & 15 & 832 & Tununguá \\
\hline 15 & 676 & San Miguel de Sema & 15 & 835 & Turmequé \\
\hline 15 & 681 & San Pablo de Borbur & 15 & 837 & Tuta \\
\hline 15 & 686 & Santana & 15 & 839 & Tutasa \\
\hline 15 & 690 & Santa María & 15 & 842 & Úmbita \\
\hline 15 & 693 & Santa Rosa de Viterbo & 15 & 861 & Ventaquemada \\
\hline 15 & 696 & Santa Sofía & 15 & 879 & Viracachá \\
\hline 15 & 720 & Sativanorte & 15 & 897 & Zetaquira \\
\hline 15 & 723 & Sativasur & & & \\
\hline
\end{tabular}

Fuente: DANE - DIVIPOLA 